genre par les élytres allongés, a épaules nulles, et me parait devoir prendre place près de subplana Desbr. (Frelon, II, p. 4) dont elle diftère par le $2^{\mathrm{e}}$ article des antennes plus long, presque aussi long que le $1^{\mathrm{er}}$, par les soies plus distinctes du dessus du corps et probablement par la ponctuation moins forte du prothorax.

Rhytirrhinus longulus, var. longipennis, nov. - Elongatus, sut angustatus, nigro-piceus, squamulis brunneis aut subflavidis ornatus, antennis nigro-piceis, pedibus rufescentibus; rostro robusto, substriato punctato; thorace subquadrato, antice et postice mediocre attenuato, in medio et lateraliter sulcato aut plus minusve impresso (impressis anticis obliquis); elytris longissimis, antice subparallelis, postice stragulatis, mediocre costatis, interstitiis biseriato punctatis (punctis grandis, subrotundatis) et setulosis. - Long. : כ̆ mill.

Algérie : Crète du Djebel Djurjura (coll. Peyerimhoff et Pic).

Cette variété se reconnaitra a première vue par sa forme étroite et allongée, ses élytres étant particulièrement longs, distinctement étranglés avant le sommet et prolongés ensuite en diminuant et s'infléchissant.

\title{
Description d'un Onitis nouveau d'Algerie [COL.]
}

par H. Tondu.

Onitis Theryi, nov. sp. — Long. : 21 mill.; lat. : 9 mill. - Noir terne. Chaperon demi-circulaire, échancré en avant, à angles antérieurs relevés et saillants en lobes un peu plus prononcés que dans O. irroratus Rossi. Antennes non pubescentes, à articles 2, 3, 4 et $\ddot{3}$ roux sur la moitié de leur longueur. Menton transverse, non échancré antérieurement. Palpes labiaux garnis de longues soies noires, serrées. Prothorax grand, dilaté, un peu plus large que long, entièrement reborde, arrondi sur les còtés en avant, légèrement sinué au-dessus des augles postérieurs, qui sont très arrondis; rebord latéral crénelé et légèrement cilié. Ponctuation du prothorax un peu ràpeuse, assez forte en avant, très faible et peu dense sur la partie postérieure. Écusson bien distinct, rugueusement et densément ponctué. Élytres subdéprimés, presque parallèles, un peu plus larges à la base, sinués sur les cotés, à stries de points obsolètes donnant comme dessin l'aspect d'une couture faite a la machine. Interstries plans, marqués de deux lignes irrégulières de points, ceux-ci peu denses, a peine pronon- 
cés sur le disque, mieux marqués vers le calus huméral. Hanches antérieures coniques, fortement et densément ponctuées au sommet, qui est garni d'une touffe de poils noirs serrés et assez longs. Pattes assez robustes. Jambes antérieures tridentées extérieurement, les quatre autres élargies et digitées au sommet, et dentées extérieurement. Cuisses antérieures échancrées intérieurement à la base, munies en dedans, vers leur partie médiane, d'une lamelle doublement anguleuse, de 2 mill., כ̋ de long sur 1 mill. de large, terminées au sommet par une forte épine interne. Prosternum portant à sa partie posté rieure deux longues dents ciliées à leur bord interne, divergentes, naissant entre les hanches antérieures et à leur base, et ayant la pointe dirigée vers les hanches intermédiaires. Mesosternum déclive. Metasternum assez saillant, fortement tuberculeux. Tarses postérieurs densément et longuement ciliés, à articles triangulaires; le premier grand, plus long que les deux suivants réunis; les autres graduellement plus courts et étroits; le dernier terminé par un crochet unique, petit, de couleur rousse, recourbé en dedans.

Présente à première vue l'aspect de Chironitisfurcifer Rossi, mais en diffère par les caractères ci-après :

Forme plus trapue, corselet plus arrondi, dents sternales plus longues et plus effilées, metasternum plus fortement tuberculeux, jambes antérieures tridentées, tarses postérieurs terminés par un crochet unique.

Beni Mora, banlieue de Biskra [17 août 1906]. - Un exemplaire ơ de ma collection.

Je suis heureux de dédier cette espèce à mon ami André Théry.

\section{Description de deux espèces nouvelles de Depressaria d'Algérie [LÉP.]}

\section{par P. Chrétien.}

Depressaría echinopella, nov. sp. - Envergure : 2ö mill. Ailes supérieures d'un ocracé jaunâtre clair, teinté un peu d'orangé près de la base, assombri légèrement de brunâtre au delà du milieu et sur les nervures. Elles présentent seulement un tout petit point noir près de la sous-costale avant le milieu, un autre point près de la - tin du disque au milieu et quelques écailles brunes figurant des points 


\section{$2 \mathrm{BHL}$ Biodiversity Heritage Library}

1907. "Description d'un Onitis nouveau d'Algerie." Bulletin de la Société entomologique de France 1907, 275-276. https://doi.org/10.5962/bhl.part.4579.

View This Item Online: https://www.biodiversitylibrary.org/item/38671

DOI: https://doi.org/10.5962/bhl.part.4579

Permalink: https://www.biodiversitylibrary.org/partpdf/4579

\section{Holding Institution}

Smithsonian Libraries

\section{Sponsored by}

Smithsonian

\section{Copyright \& Reuse}

Copyright Status: NOT_IN_COPYRIGHT

This document was created from content at the Biodiversity Heritage Library, the world's largest open access digital library for biodiversity literature and archives. Visit BHL at https://www.biodiversitylibrary.org. 